\title{
Acolhimento em saúde mental e atendimento psicológico
}

DOI: dx.doi.org/10.18616/nrm10

João André Rodrigues

Fabiane Ferraz

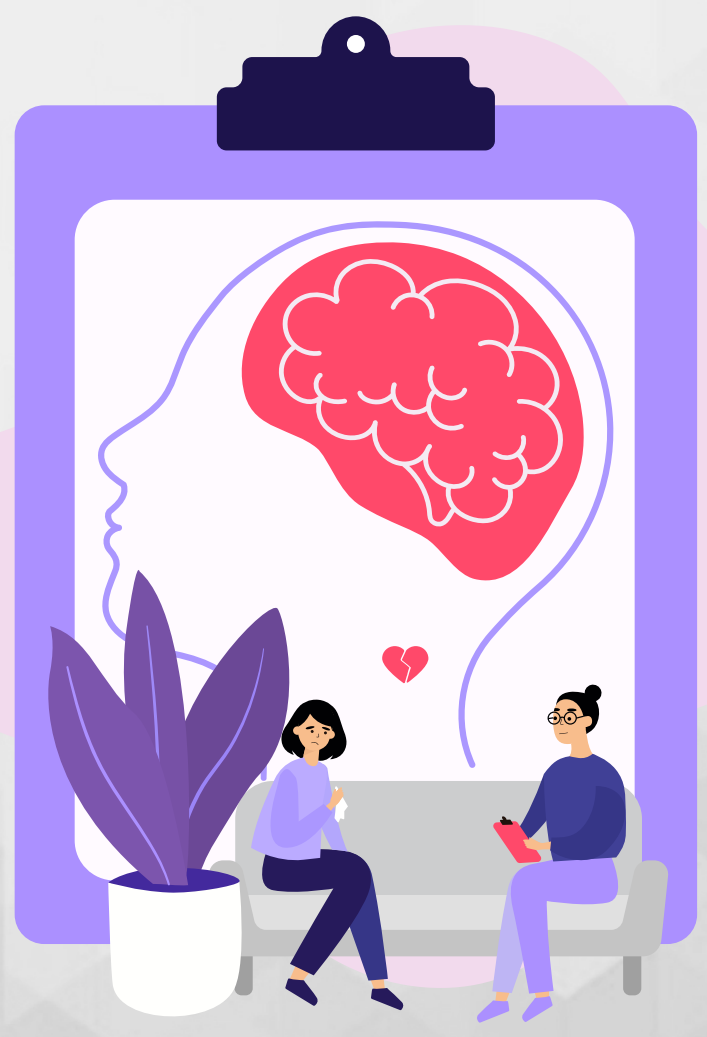


A pandemia da Covid-19 mudou a forma como vivemos e nos relacionamos com o mundo à nossa volta. Isso está nos afetando em maior ou menor proporção de forma sensível, pois desencadeia uma série de emoções e novas situações que são potencialmente geradoras de sofrimento.

O distanciamento social e as restrições de acesso a espaços físicos de cuidado em saúde mental oportunizaram o conhecimento e a construção de iniciativas de oferta de cuidados em saúde mental, mediadas por meio de tecnologias.

Cuidar de nossa saúde mental se trata de uma prerrogativa para que consigamos nos adequar a essa nova organização à qual a sociedade está tendo que se adaptar. Para tanto, é indispensável conhecermos alguns serviços que ofertam, de modo gratuito, apoio psicológico para enfrentarmos os novos desafios impostos pela situação que estamos vivenciando.

Seguem alguns serviços remotos que ofertam apoio psicológico:

\section{ACOLHER UNESC \\ 1}

TELEATENDIMENTO DE SAÚDE MENTAL EMTEMPOS DE COVID-19

\section{Programa Acolher Unesc Covid-19}

Ação da Universidade do Extremo Sul Catarinense, que coloca sua equipe de psicólogos à disposição da comunidade, unindo esforços no combate à pandemia que o

mundo enfrenta.

O serviço funciona de segunda a sexta-feira, das $8 \mathrm{~h}$ às $20 \mathrm{~h}$, pelo contato (48) 9.9644.1887.

Para solicitar atendimento, você deve enviar uma mensagem de texto via WhatsApp, dizendo “Oi”, e escolher a opção 5.

bem.care

\author{
Acessar Site
}

Aplicativo que oferece atendimento psicológico on-line, $100 \%$ gratuito, durante 6 meses, até o dia 30/09/2020. 


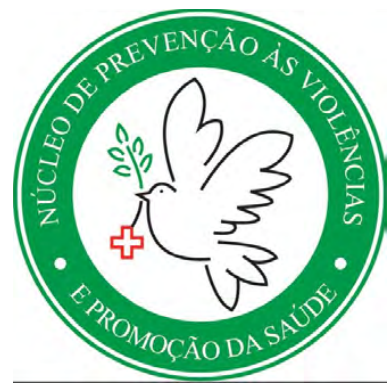

O NUPREVIPS é um serviço da prefeitura municipal de Criciúma em parceria com a UNESC.

Trata-se de um serviço de assistência a crianças, adolescentes, adultos e idosos vítimas de qualquer tipo de violência: psicológica/moral, financeira/econômica, sexual, institucional, negligência, física, trabalho infantil, tortura, tráfico de seres huma-

nos, suicídio e bullying.

O serviço funciona de segunda a sexta-feira, das $8 \mathrm{~h}$ às $12 \mathrm{~h}$ e das $13 \mathrm{~h}$ às $17 \mathrm{~h}$, nas Clínicas de Enfermagem da UNESC. Fone: (48) 3431-2764.

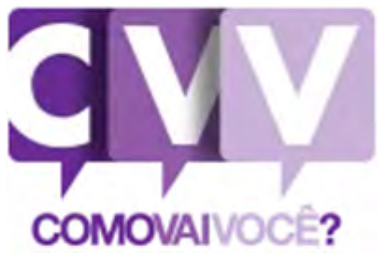

\section{Chat}

O CVV - Centro de Valorização da Vida realiza apoio emocional e prevenção do suicídio, atendendo voluntária e gratuitamente todas as pessoas que desejam e precisam conversar, sob total sigilo, por telefone, e-mail e/ou chat, 24 horas, todos os dias.

E-mail

Fone: 188

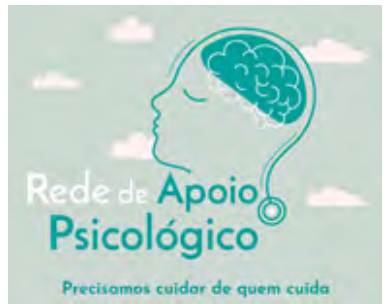

Acessar Site
Plataforma que conecta trabalhadores da saúde que estão na linha de frente do combate à Covid-19 a psicólogas e psicólogos voluntários dispostos a atendê-los. Se temos uma certeza, é a de que a solidariedade é a nossa maior força neste momento! 